\title{
Synthesis, Crystal Growth, Structural, Optical, Thermal and Mechanical Properties of Semiorganic Nonlinear Optical Material: L-Cystine Dihydrochloride
}

\section{T. Uma Devi ${ }^{{ }^{*}}$, N. Lawrence ${ }^{b}$ R. Rameshbabu' ${ }^{c}$ S. Selvanayagam ${ }^{d}$, Helen Stoeckli-Evans ${ }^{e}$, G. Bhagavannarayana ${ }^{\mathrm{f}}$, K. Ramamurthi ${ }^{\mathrm{c}}$}

${ }^{\mathrm{a}}$ Department of Physics, Government Arts College for Women, Pudukkottai -622001, India.

bepartment of Physics, St.Joseph's College, Tiruchirappalli-620002, India.

${ }^{\mathrm{c}}$ School of Physics, Bharathidasan University, Tiruchirappalli-620024, India.

${ }^{\mathrm{d}}$ Department of Physics, Kalasalingam University, Krishnan Koil - 626190

${ }^{\mathrm{e}}$ Institute of Physics, University of Neuchâtel, Neuchâtel, India

${ }^{\mathrm{f}}$ Materials Characterization Division, National Physical Laboratory, New Delhi-110 012, India

*Corresponding author: kavin_shri@yahoo.co.in

\begin{abstract}
L-Cystine dihydrochloride, a semiorganic nonlinear optical material, was synthesized and a single crystal was grown from aqueous solution. Low temperature $(173 \mathrm{~K})$ crystal structure measurement was carried out, and it reveals that the crystal belongs to noncentro symmetric space group C2. The structural perfection of the grown crystal was analyzed by high-resolution $X$-ray diffraction (HRXRD) rocking curve measurements. Fourier transform infrared (FTIR) spectroscopic studies were also performed for the identification of different vibrational modes of the fundamental groups present in the compound. The UV-vis transmission spectrum was recorded in the range 200-1000 $\mathrm{nm}$. The second harmonic conversion efficiency was determined using the Kurtz powder technique; which is 0.35 times that of KDP. Thermal properties of LCystine Dihydrochloride were studied by TGA and DTA.
\end{abstract}

Keywords: crystal structure, amino-acid, coordination compounds, thermal properties

\section{INTRODUCTION}

Extensive studies have been made on the synthesis and crystal growth of nonlinear optical (NLO) materials over the past decade because of their potential applications in the field of 
telecommunications, optical signal processing and optical switching ${ }^{1,2}$. These applications depend upon the various properties of the materials, such as transparency, birefringence, refractive index, dielectric constant, thermal, photochemical and chemical stability. Organic crystals have large nonlinear susceptibilities compared to inorganic crystals. However these crystals have certain limitations such as increased optical absorption, narrow transparency window and poor mechanical and thermal stability. Inorganic crystals have excellent mechanical and thermal properties but possess relatively low optical nonlinearities because of the lack of $\pi$ electron delocalization. Combining the high optical nonlinearity and chemical flexibility of organics with thermal stability and excellent transmittance of inorganics, semiorganic materials have been proposed and are attracting a great deal of attention in the field of nonlinear optics ${ }^{3,4}$. Complexes of amino acids with inorganic salts are promising materials for optical second harmonic generation (SHG), as they aptly fit in this context with such properties. Amino acids are interesting materials for NLO application as they contain a proton donor carboxyl acid ($\mathrm{COO})$ group and the proton acceptor amino $\left(-\mathrm{NH}_{2}\right)$ group in them. A series of semi-organic compounds such as 1-histidinium hydrogen malate ${ }^{5}$, L-arginine diphosphate ${ }^{6}$, L-Lysine monohydrochloride dihydrate ${ }^{7}$, L-histidine hydrochloride monohydrate ${ }^{8}$ and L-glutamic acid hydrochloride ${ }^{9}$ have been reported with moderately high mechanical and chemical stability. Our laboratory is engaged in finding new materials for NLO applications and some of these were reported recently ${ }^{10-13}$.

L-cystine dihydrochloride $\left(\mathrm{C}_{6} \mathrm{H}_{12} \mathrm{~S}_{2} \mathrm{~N}_{2} \mathrm{O}_{4} \cdot 2 \mathrm{HCl}\right)$ is yet another semiorganic nonlinear optical material. L-Cystine is a sulfur containing amino acid. The chirality of L-cystine enforces noncentrosymmetry of crystal structures of its compounds. This is an important aspect in addition to chemical and conformational flexibility for the search for new non-centrosymmetrical materials with certain desired physical properties, such as in the field of non-linear optics ${ }^{3}$. In this paper, we report for the first time on the growth of bulk crystal of L-cystine dihydrochloride (LCDHCL) using temperature reduction method and its characterization by single crystal x-ray diffraction (XRD), High resolution X-ray diffraction (HRXRD), Fourier Transform infrared spectroscopy (FTIR), UV-Vis-NIR, thermal and microhardness studies.

\section{EXPERIMENTAL PROCEDURE}

The LCDHCL was synthesized by dissolving $1 \mathrm{M}$ of L-cystine in $2 \mathrm{M}$ of hydrochloric acid in double distilled water at $50{ }^{\circ} \mathrm{C}$. The fully reacted solution was filtered and crystalline salt was obtained by evaporation of filtered solution. The crystalline salt formed was further purified by re-crystallization process in double distilled water. Solubility of LCDHCL in double distilled water was determined in the temperature range of $30-55^{\circ} \mathrm{C}$.

From the knowledge of these data, saturated solution of LCDHCL was prepared at $35^{\circ} \mathrm{C}$ from recrystallized salt and this solution was filtered with microfilters and placed in a constant 
temperature bath having an accuracy of $\pm 0.01{ }^{\circ} \mathrm{C}$. One of the better quality crystals obtained from slow evaporation of the solution at room temperature was used as the seed crystal. Single crystal of LCDHCL was grown by the slow cooling method by reducing the temperature from 35 ${ }^{\circ} \mathrm{C}$ at the rate of $0.1{ }^{\circ} \mathrm{C}$ per day. Well-developed crystal of size $20 \times 6 \times 5 \mathrm{~mm}^{3}$, harvested in a growth period of 10 days, is shown in Figure 1.

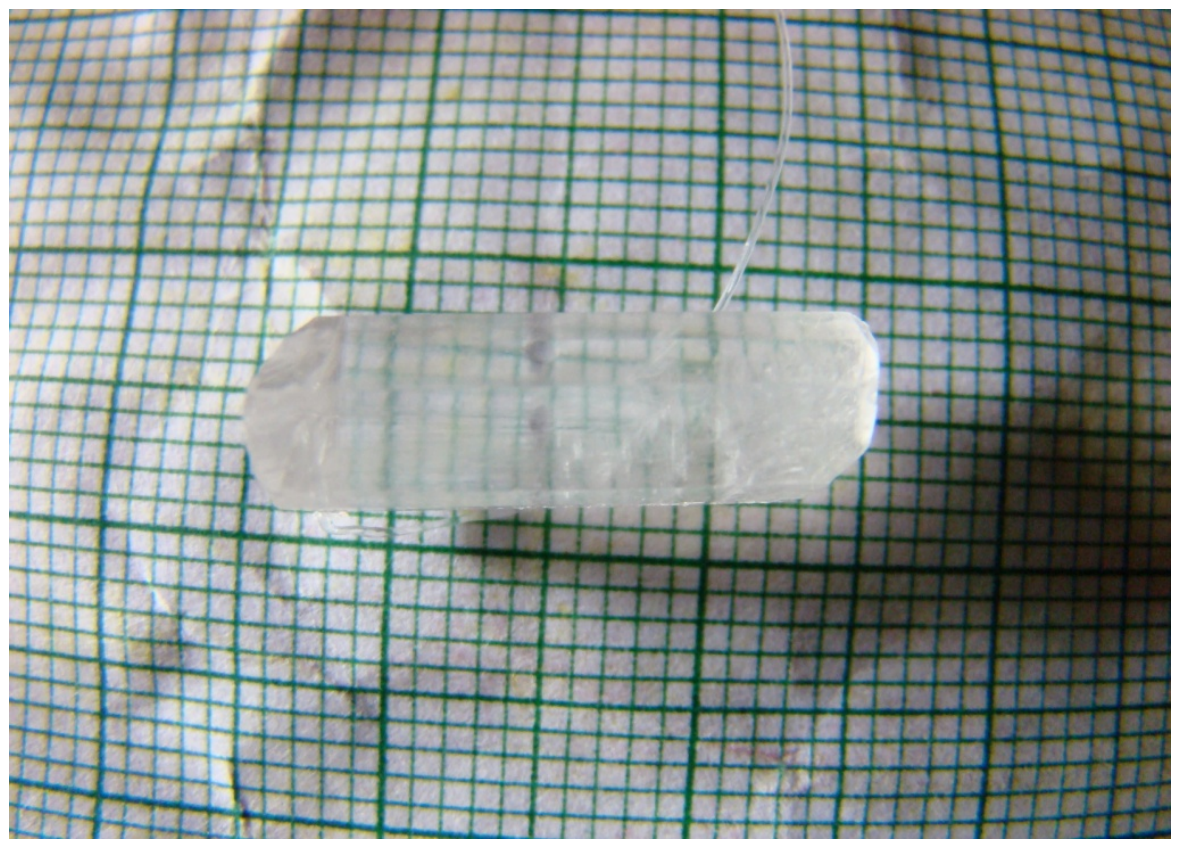

Figure 1. As grown crystal of LCDHCL.

\section{RESULTS AND DISCUSSION}

\subsection{X-ray Diffraction}

Data set was obtained using a Stoe Image Plate Diffraction System using Mo Ka graphite monochromated radiation at $173 \mathrm{~K}$ using phi \& omega scans method. The structure was solved by Direct methods using the programme SHELXS97 and refined by full-matrix least squares method using SHELXL97. The R-values of the full-matrix least squares refinement is given in Table 1. The H-atoms could all be located in Fourier difference maps. The water $\mathrm{H}$-atoms were freely refined, while the remainder of the $\mathrm{H}$-atoms were included in calculated positions and treated as riding atoms using SHELXL default parameters. CCDC 653578 contains the supplementary crystallographic data for the title compound. These data can be obtained from free of charge from the Cambridge Crystallographic Data Centre via the website of www.ccdc.cam.ac.uk/data_request/cif. 
The X-ray study confirmed the molecular structure and atomic connectivity for the title compound as illustrated in Figure 2a. In the title compound the molecule resides on a crystallographic twofold axis, which runs through the central S-S bond. The bond distance S1$\mathrm{S}^{\mathrm{i}}$ of 2.040 (1) $\AA$ [symmetry code: (i) 1-x, y, 1-z] confirms the S-S single bond character. The geometry of the cystine residues are comparable to the related literature values. Both half molecule adopts $\mathrm{R}$ configuration with the atoms $\mathrm{C}^{2} / \mathrm{N} 1 / \mathrm{C} 1 / \mathrm{C} 3 / \mathrm{H} 2$. The molecular structure is stabilized by strong intramolecular $\mathrm{N}-\mathrm{H} . . . \mathrm{Cl}$ hydrogen bond involving atoms $\mathrm{N} 1-\mathrm{H} 1 \mathrm{C} . . . \mathrm{Cl}$. The crystal packing is stabilized by strong intermolecular $\mathrm{N}-\mathrm{H} . . . \mathrm{Cl}$ and $\mathrm{O}-\mathrm{H} . . . \mathrm{Cl}$ hydrogen bonds. The Chlorine atom act as a trifurcated acceptor atom for two intermolecular and one intramolecular hydrogen bonds involving with all the three hydrogen atoms attached to N1. Two of these hydrogen bonds run along ' $b c$ ' plane and one run along ' $a c$ ' plane (Figure 2b). The acid group hydrogen atom involves $\mathrm{O} 2-\mathrm{H} 2 \mathrm{O} \ldots \mathrm{Cl} 1$ intermolecular hydrogen bond in the equivalent position of $\mathrm{x}, \mathrm{y}-1,1+\mathrm{z}$ The molecules are further stabilized by weak two C-H...O intermolecular interaction involving atoms $\mathrm{C} 2-\mathrm{H} 2 \ldots \mathrm{O} 1$.

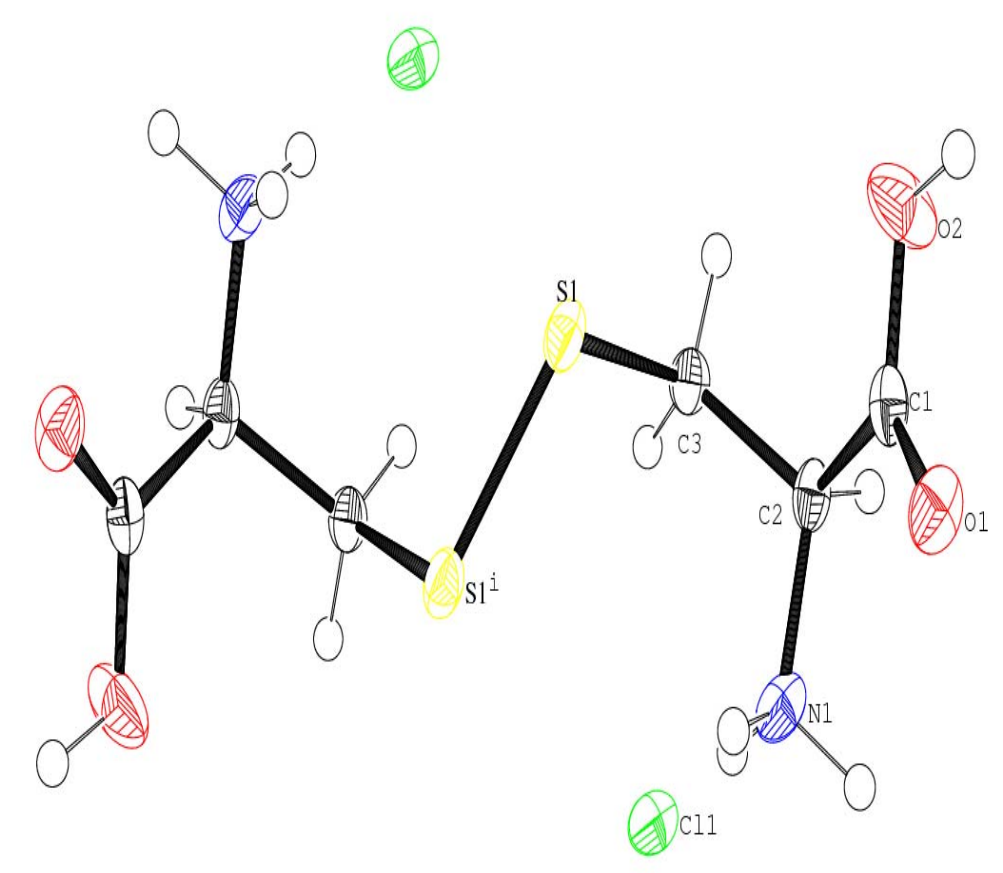

Figure 2a. ORTEP of LCDHCL showing 50\% probability ellipsoids and the labeling scheme. 


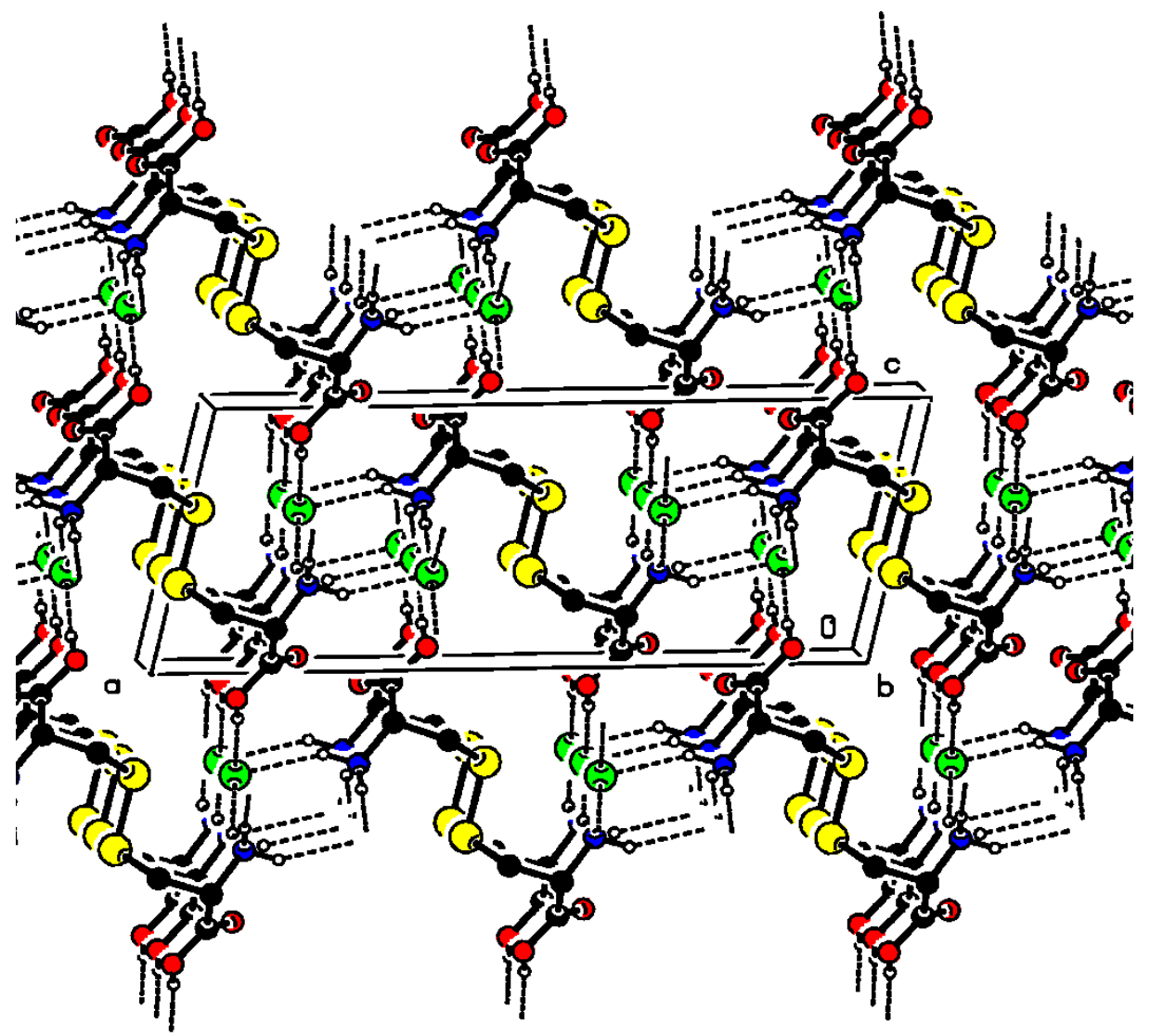

Figure 2b. A view along the $\mathrm{b}$ axis of the crystal packing of LCDHCL.

\begin{tabular}{l|l} 
Table 1. Single-Crystal X-ray & Data of LCDHCL Crystal. \\
\hline CCDC No. & $\mathrm{CCDC} 653578$ \\
Formula & $\mathrm{C}_{6} \mathrm{H}_{14} \mathrm{Cl}_{2} \mathrm{~N}_{2} \mathrm{O}_{4} \mathrm{~S}_{2}$ \\
Formula weight & 313.23 \\
Crystal System & Monoclinic \\
Space group & $\mathrm{C} 2$ \\
$\mathrm{a}(\AA)$ & $18.4405(14)$ \\
$\mathrm{b}(\AA)$ & $5.2166(6)$ \\
$\mathrm{c}(\AA)$ & $7.2191(6)$ \\
$\alpha\left({ }^{\circ}\right)$ & 90 \\
$\beta\left(^{\circ}\right)$ & $103.850(6)$ \\
$\gamma\left(\left(^{\circ}\right)\right.$ & 90 \\
$\mathrm{~V}\left(\AA^{3}\right)$ & $673.62(11)$ \\
$\mathrm{R}_{1}$ & 0.0178 \\
$\mathrm{wR}_{2}$ & 0.0446 \\
Flack parameter & $-0.03(5)$ \\
\hline
\end{tabular}


The freshly ground powder sample of LCDHCL was subjected to powder X-ray diffraction analysis with a monochromated $\mathrm{CuK} \alpha$ radiation $(\lambda=1.5406 \AA)$. The powder XRD patterns are indexed and shown in Figure 3.

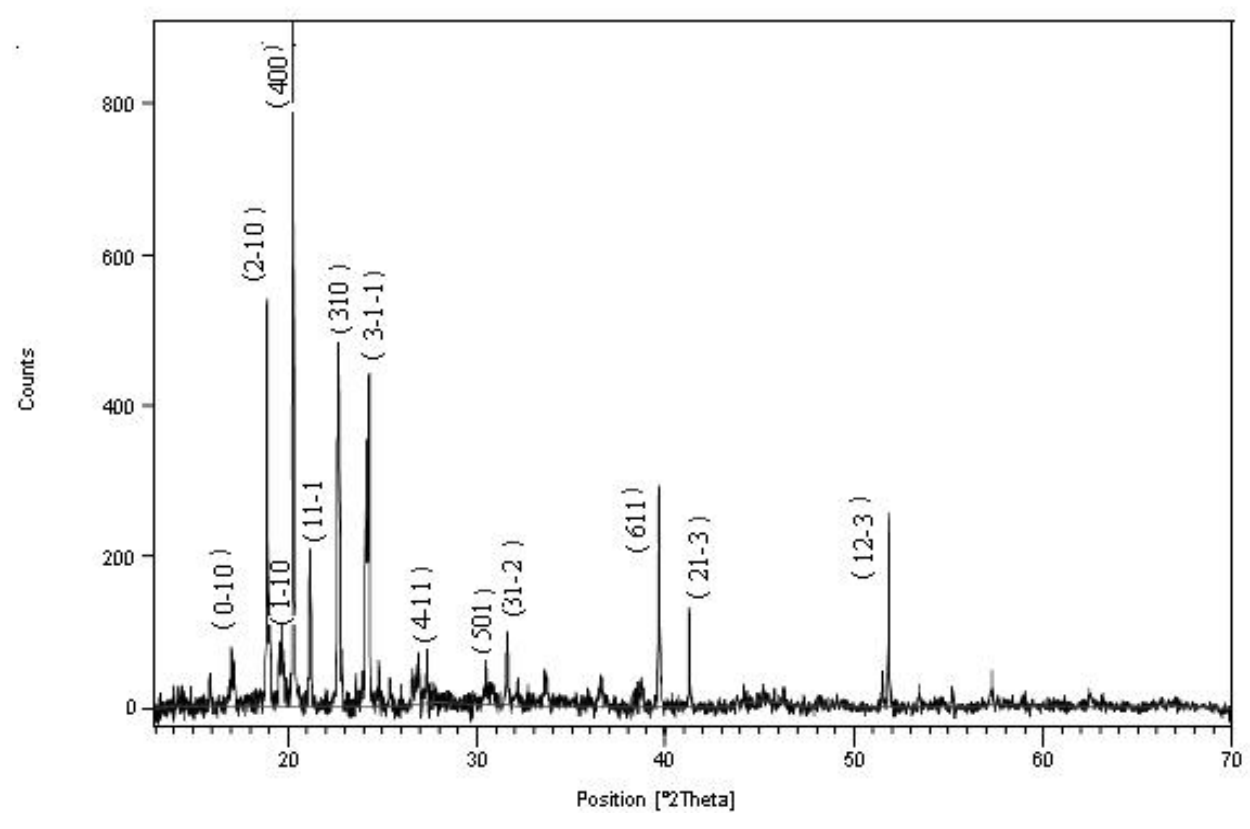

Figure 3. Powder X-ray diffraction of LCDHCL.

Figure 4 shows the high-resolution X-ray diffraction curve (DC) recorded for a typical LCDHCL single crystal specimen using (400) diffracting planes in symmetrical Bragg geometry by employing the multicrystal X-ray diffractometer with $\mathrm{MoK} \alpha_{1}$ radiation. The solid line (convoluted curve) is well fitted with the experimental points represented by the filled rectangles. On deconvolution of the diffraction curve, it is clear that the curve contains an additional peak, which is 57 arc s away from the main peak. This additional peak depicts an internal structural very low angle (tilt angle $\leq 1$ arc min) boundary ${ }^{14}$ whose tilt angle (misorientation angle between the two crystalline regions on both sides of the structural grain boundary) is 59 arc s from its adjoining region. The FWHM (full width at half maximum) of the main peak and the very low angle boundary are respectively 52 and 46 arc s. Though the specimen contain a very low angle boundary, the relatively low angular spread of around 300 arc s of the diffraction curve and the low FWHM values show that the crystalline perfection is reasonably good. Thermal fluctuations or mechanical disturbances during the growth process could be responsible for the observed very low angle boundary. 


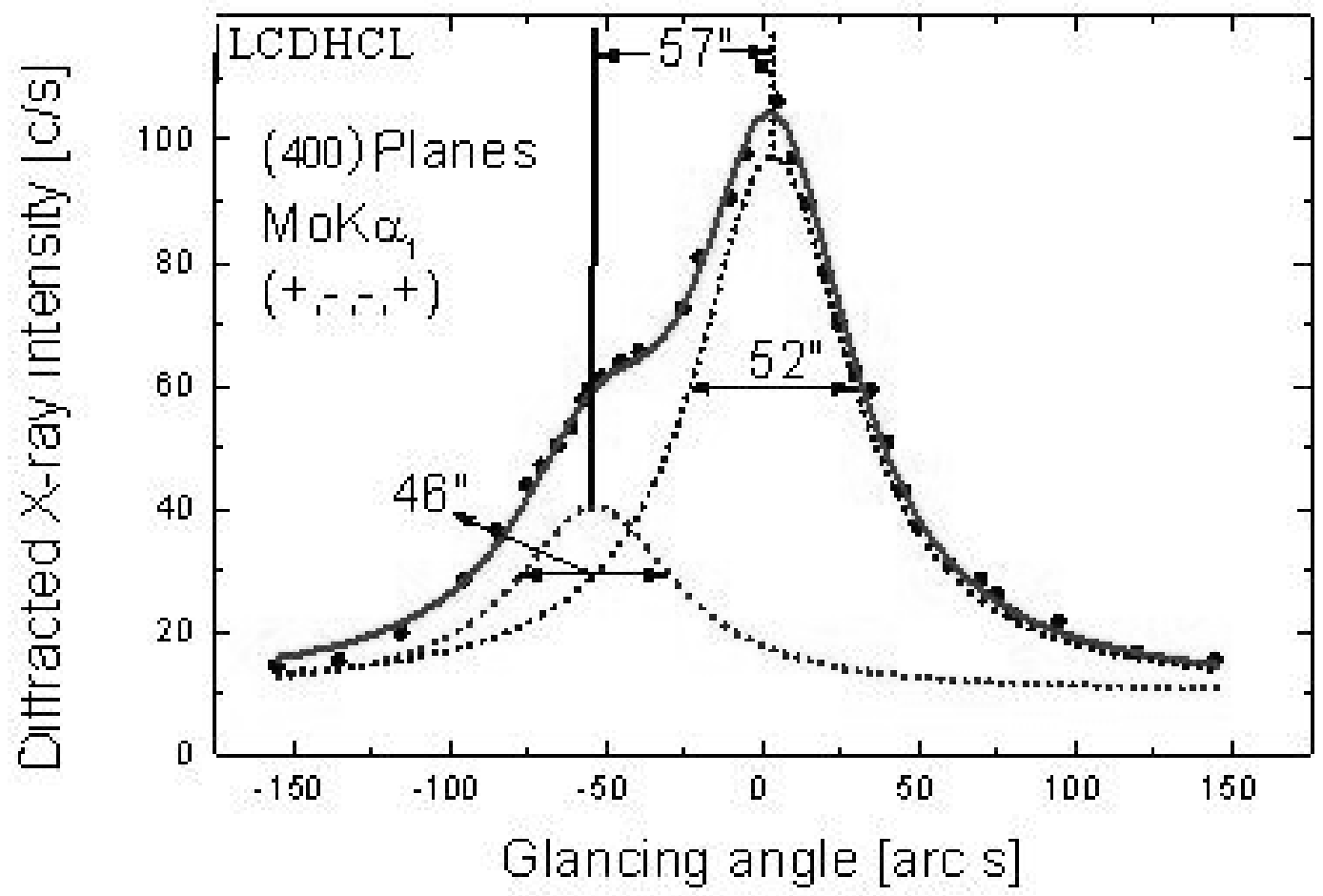

Figure 4. High-resolution diffraction curve of LCDHCL.

\subsection{Fourier Transform Infrared Spectrum}

The Fourier Transform Infrared (FTIR) spectrum of LCDHCL (Figure 5) was recorded at room temperature in the spectral range $400-4000 \mathrm{~cm}^{-1}$ by $\mathrm{KBr}$ pellet method using the Perkin Elmer grating Infrared spectrophotometer. The peak at $1730 \mathrm{~cm}^{-1}$ is characteristic of $\alpha$-amino acid hydrochlorides $^{10}$. Presence of the functional groups of L-cystine, were identified and the vibrational frequencies are compared in Table 2 with the corresponding frequencies of the parent reactant of L-cystine. From Table 2 one can observe that the vibrational frequencies except $\mathrm{CH}_{2}$ wagging and C-C deformation are not modified appreciably in the LCDHCL crystal. 


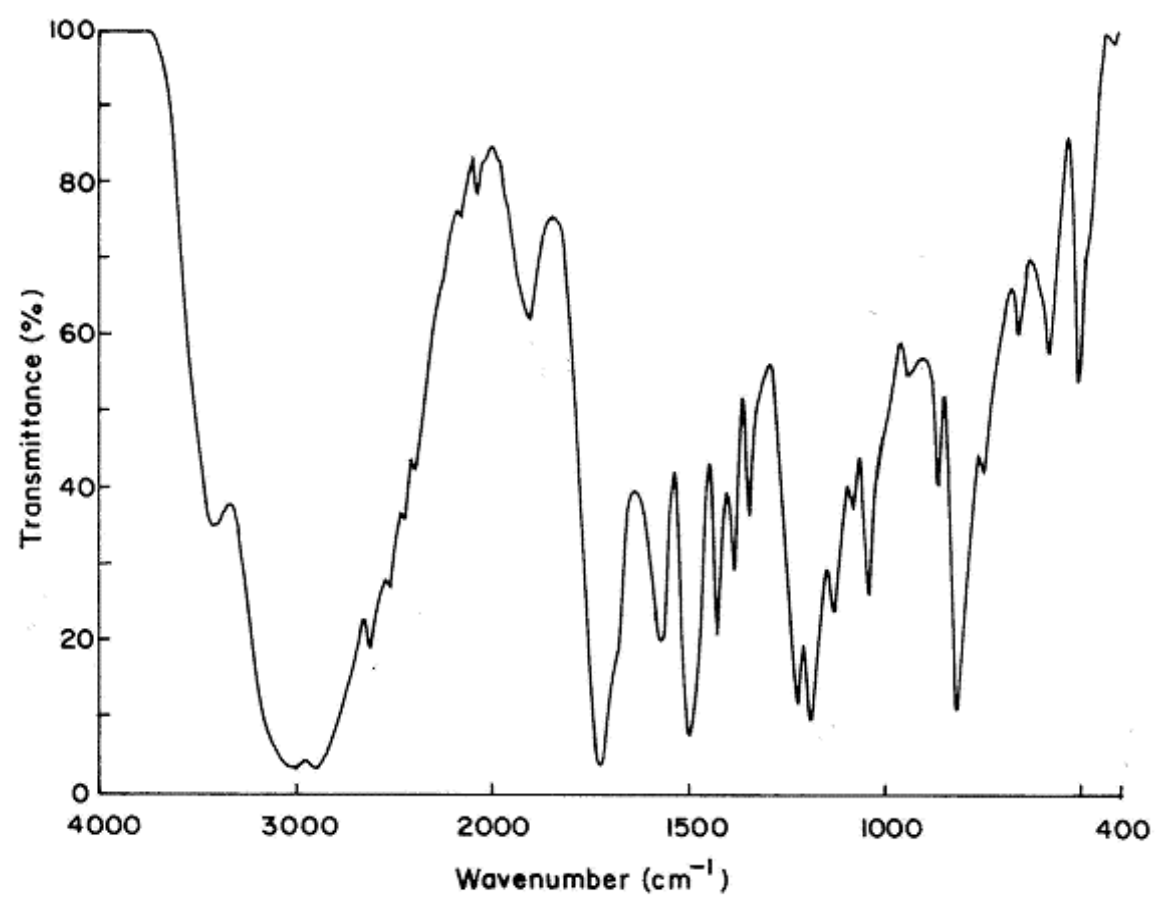

Figure 5. FTIR spectrum of LCDHCL.

Table 2. Band assignment of FTIR spectrum of LCDHCL

Wave number $\left(\mathrm{cm}^{-1}\right)$

assignments[16]

L-cystine [15]

LCDHCL

(Present Work)

3429

3413

NH asymmetric stretching

3030

3020

$\mathrm{CH}$ broad band stretching

2096

2083

$\mathrm{NH}_{3}^{+}$stretching

1585

1570

$\mathrm{NH}_{3}{ }^{+}$deformation

1489

1503

$\mathrm{COO}^{-}$stretching

$\mathrm{CH}_{2}-\mathrm{CO}$ deformation 


\subsection{Optical Transmission Spectrum}

Optically transparent single crystal of thickness $2 \mathrm{~mm}$ was used to record the optical transmittance spectrum by employing Varian Cary 5E UV - Vis - NIR spectrophotometer in the range 200 and $1000 \mathrm{~nm}$ (Figure 6).Transmittance is about $70 \%$ in the range of $400-1000 \mathrm{~nm}$ and the lower cutoff is at $300 \mathrm{~nm}$. Hence the $L C D H C L$ crystal can be used as a potential material for frequency doubling.

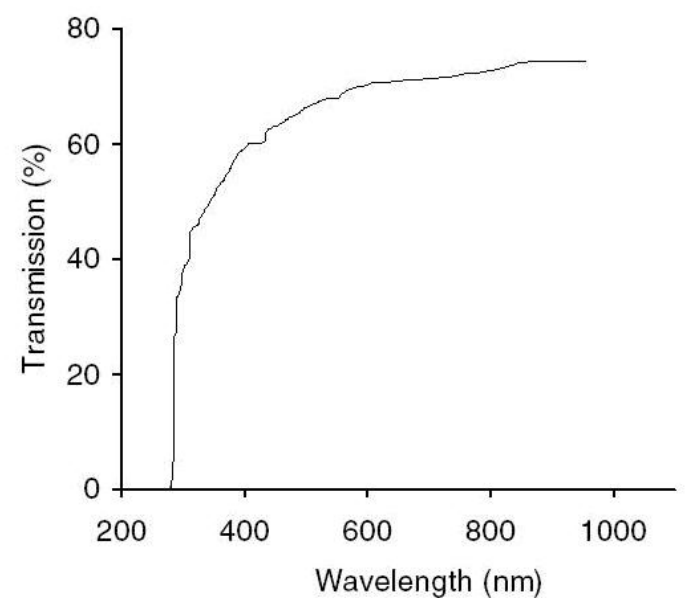

Figure 6. UV-Vis spectrum of LCDHCL. 


\subsection{Microhardness Studies}

Vicker's microhardness values were estimated by employing REICHERT MD 4000E ULTRA microhardness tester for different loads on the polished face of LCDHCL. Vickers microhardness number $\left(\mathrm{H}_{\mathrm{v}}\right)$ was calculated using the relation, $\mathrm{H}_{\mathrm{v}}=1.8544\left(\mathrm{P} / \mathrm{d}^{2}\right) \mathrm{kg} / \mathrm{mm}^{2}$, where $\mathrm{P}$ is the indenter load in $\mathrm{kg}$ and $\mathrm{d}$ is the diagonal length of the impression in $\mathrm{mm}$. Figure 7 shows the variation of Vickers hardness values with load. The hardness value increases up to a load of $100 \mathrm{~g}$ and decreases for $200 \mathrm{~g}$. Cracks develop around the indentation mark above the load of $200 \mathrm{~g}$. The work hardening coefficient $\mathrm{n}$ was calculated from Meyer's law ${ }^{17}$. The $\mathrm{n}$ value calculated by plotting $\log \mathrm{P}$ against $\log \mathrm{d}$ for LCDHCL crystal on (001) plane is 2 . Onitsch ${ }^{18}$ inferred that a value of $\mathrm{n}$ lies between 1 and 1.6 for hard materials and for soft materials it is above 1.6. Therefore calculated value of $n=2$ shows that LCDHCL is a soft material.

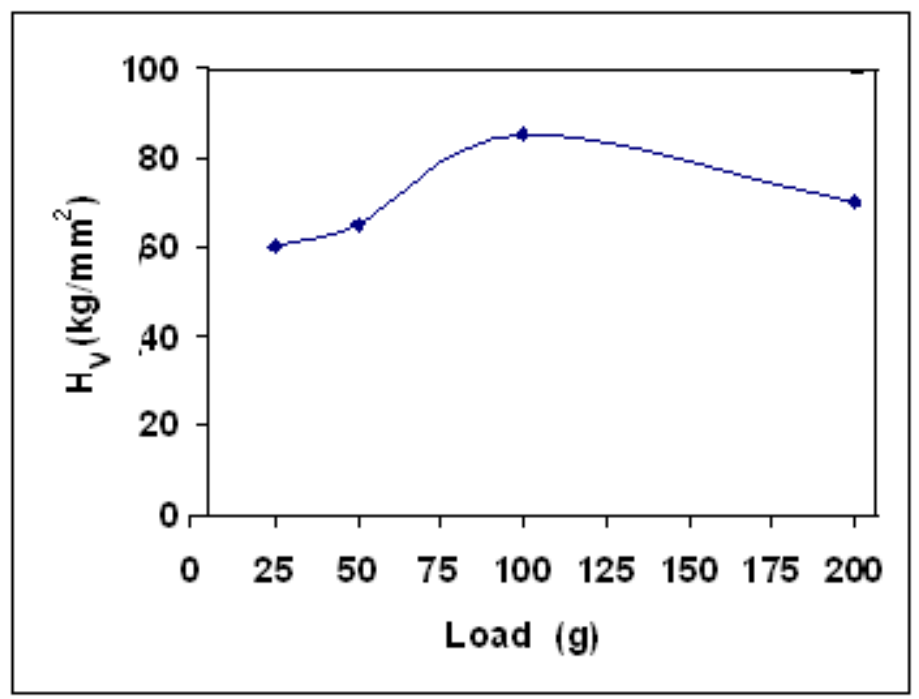

Figure 7. Variation of microhardness values with applied load

\subsection{Thermal Studies}

Thermogravimetric analysis of the LCDHCL crystal was carried out employing Perkin Elmer, US, TGA7 Analyzer between 50 and $900^{\circ} \mathrm{C}$ in the nitrogen atmosphere at a heating rate of $10^{\circ}$ $\mathrm{C} / \mathrm{min}$ (Figure 8). A small piece of crystal weighing $1.6420 \mathrm{mg}$ was used for this investigation. From the TG-DTA curves it is inferred that the melting of the material takes place in the vicinity of $235^{\circ} \mathrm{C}$. The sharpness of this endothermic peak shows the good degree of crystallinity and purity of the sample ${ }^{19,20}$. Further, it indicates no phase transition before this temperature. There is a gradual and significant weight-loss as the temperature is increased above the melting point. Sudden decomposition took place between $235{ }^{\circ} \mathrm{C}$ and $333{ }^{\circ} \mathrm{C}$ with a weight loss of $78 \%$ due to the expulsion of molecules of, $\mathrm{SO}_{2}, \mathrm{NH}_{3}$ and $\mathrm{CO}_{2}$ from the chain and the residual weight obtained at $800{ }^{\circ} \mathrm{C}$ is only $2.42 \%$. 


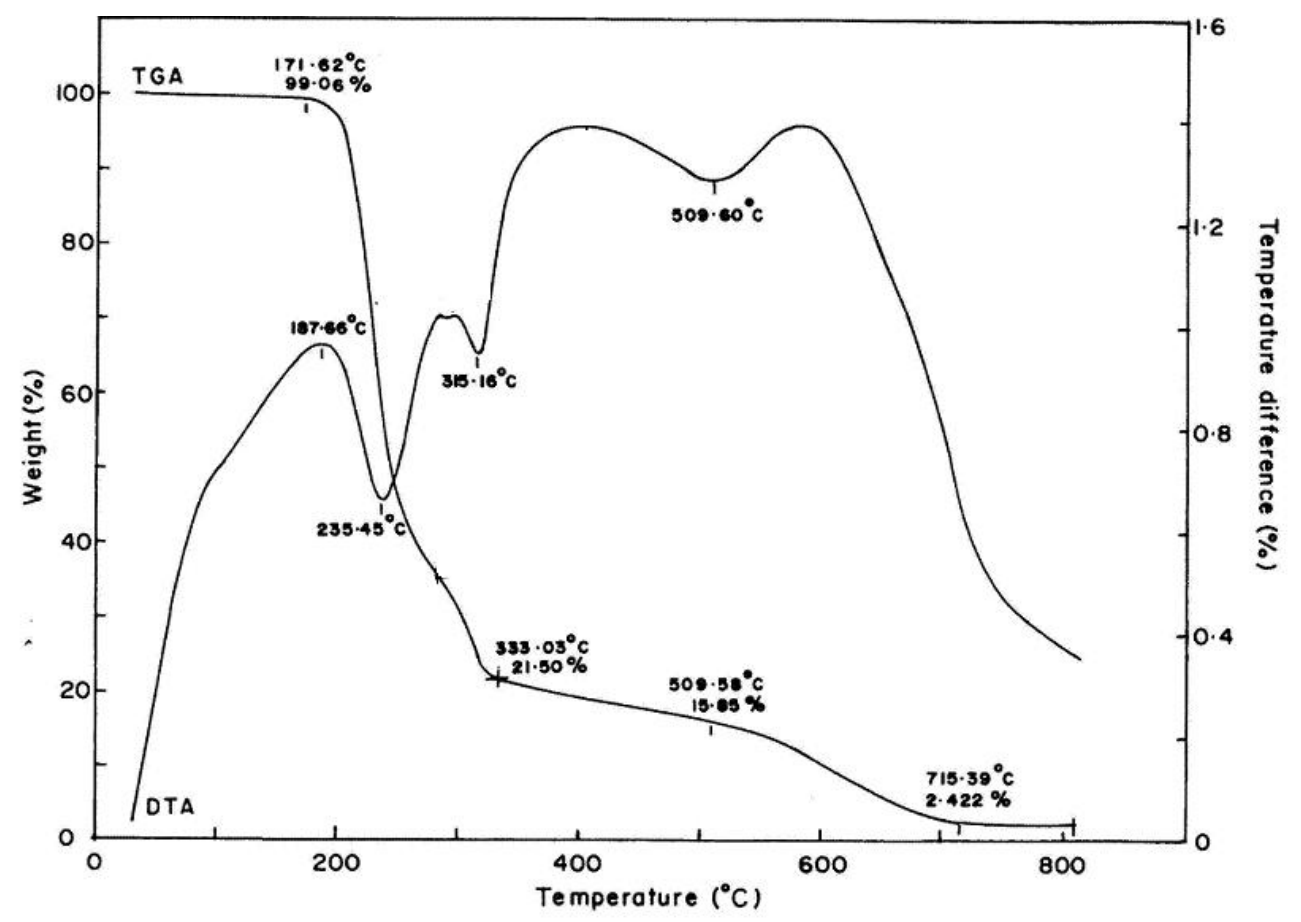

Figure 8. TG/DTA of LCDHCL.

\subsection{NLO Studies}

Kurtz ${ }^{21}$ second harmonic generation (SHG) test was performed to find the NLO property of LCDHCL crystal. The powdered crystalline sample was illuminated using Spectra Physics Quanta Ray DHS-2. Nd: YAG laser using the first harmonics output of $1064 \mathrm{~nm}$ with pulse width of $8 \mathrm{~ns}$ and repetition rate of $10 \mathrm{~Hz}$. The green radiation of $532 \mathrm{~nm}$ was collected by a photomultiplier tube (PMT- Philips Photonics - model 8563) after being monochromated (monochromator - model Triax - 550). The optical signal incident on the PMT was converted into voltage output at the CRO (Tektronix- TDS 3052B). The input laser energy incident on the powdered sample was chosen to be $5.6 \mathrm{~mJ}$. The result obtained shows that the powder SHG relative efficiency of LCDHCL is about 0.34 times that of potassium dihydrogen orthophosphate (KDP). As the second order nonlinear efficiency will vary with the particle size of the powder sample, higher efficiencies are expected to be achieved by optimizing the phase matching 22 .

\section{CONCLUSION}

Single crystals of L-cystine dihydrochloride, a semiorganic NLO material of the amino-carboxyl acid family was grown using temperature reduction technique. Single crystal X-ray diffraction study shows that LCDHCL crystallizes in a monoclinic system. A multicrystal X-ray diffractometer study reveals that the crystalline perfection of the grown crystal is reasonably 
good. The presence of functional groups such as $\mathrm{N}-\mathrm{H}, \mathrm{COO}^{-}, \mathrm{C}-\mathrm{C}, \mathrm{C}-\mathrm{H}$ and $\mathrm{C}-\mathrm{S}$ were identified. Optical transmission study shows that LCDHCL is transparent in the entire visible and in NIR region. Microhardness measurements imply that the LCDHCL comes under the soft materials category. TGA reveals that the sample is thermally stable and has relatively higher melting point. Furthermore, its nonlinear property was investigated by the Kurtz and Perry technique and the second harmonic conversion relative efficiency of powder LCDHCL is about 0.34 times that of KDP.

\section{ACKNOWLEDGEMENT}

One of the authors (T. U.) acknowledges Cauvery College for Women (Reddy Educational Trust) for providing lab facilities to carry out the research work. The authors acknowledge Prof. P. K. Das, Department of Inorganic and Physical Chemistry, Indian Institute of Science, Bangalore for extending the laser facilities for the SHG measurement.

\section{REFERENCES}

[1] P.N. Prasad and D.J. Williams. Introduction to Nonlinear Optical Effects on Molecules and Polymers, Wiley, New York (1991)

[2] D.S. Chemla and J. Zyss. In: Nonlinear Optical Properties of Organic Molecules and Crystals Vols. 1 and 2, Academic Press, Orlando (1987).

[3] M. Fleck, P. Becker, L. Bayarjargal, R. Ochrombel, L.Bohatý, Cryst. Res. Technol. 2008, 43,127-134.

[4] V. Siva shankar, R. Siddheswaran, T. Bharthasarathi, P. Murugakoothan,J.Cryst. Growth 2009, 311, 2709-2713

[5] E. de Matos Gomes, V.H. Rodrigues, M.M.R. Costa, M.S. Belsley, P.J.M. Cardoso, C.F. Gonçalves, F. Proença, J. Solid State Chem. 2006, 179, 2521-2528

[6] R. Ittychan, P. Sagayaraj, J. Cryst.Growth 2002 ,243, 356 -360.

[7] R.Ramesh Babu, N.Vijayan, R.Gopalakrishnan, P. Ramasamy ,Cryst. Res. Technol. 2006, 41, $405-410$.

[8] J. Madhavan, S. Aruna, P. C. Thomas, M. Vimalan, S. A. Rajasekar, and P. Sagayaraj, Cryst.Res. Technol. 2007, 42, $59-64$.

[9] R. Sathyalakshmi, V. Kannan, R. Bairava Ganesh, and P. Ramasamy Cryst. Res. Technol. 2007, 42, 78-83.

[10] T. Uma Devi , N. Lawrence, R. Ramesh Babu, K. Ramamurthi J. Cryst. Growth 2008, 310, 116-123.

[11] T. Uma Devi , N. Lawrence, R. Ramesh Babu, K. Ramamurthi Spectrochim. Acta A 2008, 71, 340-343 
[12] T. Uma Devi , N. Lawrence, R. Ramesh Babu, S. Selvanayagam, Helen Stoeckli-Evans, K. Ramamurthi Cryst. Growth Des. 2009, 9, 1370 -1374.

[13] T. Uma Devi , N. Lawrence, R. Ramesh Babu, K. Ramamurthi Mat. Res. India, 2008,5, 397-402

[14] G. Bhagavannarayana, R.V. Ananthamurthy, G.C.Budakoti, B. Kumar, K.S. Bartwal, J. Appl. Cryst. 2005, 38, 768 -771.

[15] E. Ramachandran, S. Natarajan, Cryst. Res. Technol. 2004, 39, 308-312.

[16] K.Biemann, Tables of Spectral Data for Structure Determination of Organic Compounds, Springer Verlag, Berlin Heidelberg, 1989.

[17] H. Li, R.C. Bradt, J. Hard Mater. 1992, 3, 403-419.

[18] E.M.Onitsch, Mikroskopie 1947, 2, 131 -151.

[19] N. Vijayan, R. Ramesh Babu, M. Gunasekaraan, R. Gopalakrishnan, R. Kumaresan, P. Ramasamy, C. W. Lan, J. Cryst. Growth 2003, 249, 309-315.

[20] A.S.H. Hameed, G. Ravi, R. Dhanasekaran, P. Ramasamy, J. Crystal Growth 2000, 212, 227-232.

[21] S.K. Kurz, T.T. Perry, J. Appl. Phys. 1968, 39, 3798 -813.

[22] H.J. Ravindra, M.R. Suresh Kumar, C. Rai, S.M. Dharmaprakash, J. Cryst. Growth 2006, 294, 318-322 